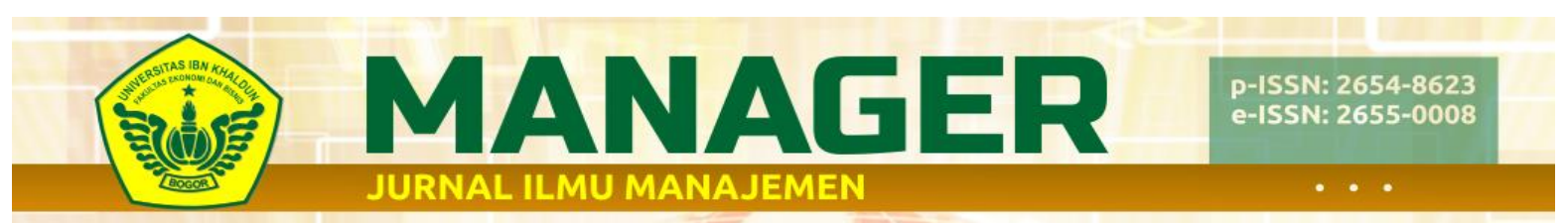

Vol. 3, No. 3, Agustus 2020, Hal 413-420

(c) (1)

http://ejournal.uikabogor.ac.id/index.php/Manager/index

\title{
PENGARUH ORGANIZATIONAL TRUST DAN ORGANIZATIONAL COMMITMENT TERHADAP ORGANIZATIONAL CITIZENSHIP BEHAVIOR
}

\author{
M.Galang Nur Alamsyah, M.Aziz Firdaus, Rachmatullaily Tinakartika Rinda \\ Fakultas Ekonomi dan Bisnis, Universitas Ibn Khaldun Bogor, Indonesia \\ Galangalamsyah@gmail.com, AzizFirdaus@uika-bogor.ac.id, Laillyrinda@yahoo.com
}

\begin{abstract}
The purpose of this study was to determine the Effect of Organizational Trust and Organizational Commitment on Organizational Citizenship Behavior Employees of BPJS Employment City of Bogor. Researchers obtained data by distributing questionnaires. The number of samples taken 48 employees. The data methods used are validity, reliability, descriptive, inferentive, multiple regression, correlation, coefficient of determination, $t$ test, $f$ test, using computer applications. It is known that $R=0.708$ is located at intervals $(0.60$ 0.799), this shows that the relationship between Organizational Trust (X1) Organizational Commitment (X2) variables to Organizational Citizenship Behavior $(Y)$ is strong and positive. This is evidenced by the results of the analysis of $F$ count 23,662> F table 3.19 so it can be concluded that $\mathrm{H} 3$ is accepted which means there is an influence of X1 (Organizational Trust) and X2 (Organizational Commitment) simultaneously on $Y(O C B)$.
\end{abstract}

Keywords: Organizational Trust; Organizational Commitment; OCB.

\begin{abstract}
Abstrak
Tujuan penelitian ini untuk mengetahui Pengaruh Organizational Trust dan Organizational Commitment Terhadap Organizational Citizenship Behavior Karyawan BPJS Ketenagakerjaan Kota Bogor. Peneliti memperoleh data dengan penyebaran kuesioner. Jumlah sampel yang diambil 48 karyawan. Metode data yang digunakan yaitu validitas, reabilitas, deskriptif, inferentif, regresi ganda, korelasi, koefisien determinasi, uji t, uji f, dengan menggunakan aplikasi komputer. Diketahui $\mathrm{R}=0.708$ terletak pada interval (0.60-0.799) hal ini menunjukan bahwa hubungan antara variabel Organizational Trust (X1) Organizational Commitment (X2) terhadap Organizational Citizenship Behavior (Y) adalah kuat dan positif. Hal ini dibuktikan oleh hasil analisis $\mathrm{F}$ hitung 23,662 >F tabel 3,19 sehingga dapat disimpulkan bahwa $\mathrm{H} 3$ diterima yang berarti terdapat pengaruh X1 (Organizational Trust) dan X2(Organizational Commitment) secara simultan terhadap Y (OCB).
\end{abstract}

Kata kunci : Organizational Trust; Organizational Commitment; OCB

\section{Pendahuluan}

Salah satu kunci sukses keberhasilan organisasi ditentukan oleh keberhasilan organisasi dalam mengelola sumber daya manusia sebagai agen inisiator dan perubahan terus menerus (sustainable change), serta pembentuk proses budaya yang secara bersama-sama meningkatkan 
kemampuan organisasi. Kinerja tim dalam organisasi sangat ditentukan oleh keterampilan anggota dalam tim (work teams). Kenyataannya, tidak semua individu mampu bekerja dalam tim, karena memerlukan kemampuan dalam individu untuk berkomunikasi secara terbuka dan jujur, bekerja sama dengan orang lain, membagi informasi, mengakui perbedaan dan mampu menyelesaikan konflik, serta dapat menekan tujuan pribadi demi tujuan tim. tim kerja pada dasarnya merupakan kebutuhan organisasi guna mendukung kelancaran operasional organisasi secara keseluruhan Organizational citizenship behavior (OCB) merupakan perilaku individu yang dipandang perlu untuk dikembangkan guna menciptakan individu yang dapat bekerja sama satu sama lain.

Organizational trust merupakan dukungan yang diberikan organisasi pada dirinya, sehingga muncul rasa kepercayaan individu kepada pimpinan bahwa setiap tindakannya didukung oleh organisasi. Namun, yang terjadi pada hari ini realita bahwa karyawan tidak memiliki kepercayaan terhadap pimpinan, terlebih pada lembaga pemerintahan. Ketika kepercayaan organisasi ini tidak dimiliki oleh karyawan maka perusahaan tidak memiliki kesempatan untuk mencapai target. Oleh sebab itu, organizational trust harus dimiliki oleh setiap individu dalam organisasi guna menciptakan organizational citizenship behavior (OCB) dikalangan individu.

Faktor lain yang mempengaruhi Organizational citizenship behavior (OCB) adalah komitmen organisasi. Komitmen dikarakterkan sebagai kemampuan psikologi seseorang dalam mengikatkan dirinya pada organisasi. Selain itu, seseorang yang memiliki komitmen akan mengidentitaskan dirinya dengan organisasi. Identitas komitmen seseorang ditunjukan dengan loyalitas yang tinggi pada organisasi dengan melaksanakan kinerja yang efektif.

organizational commitment memiliki pengaruh negative terhadap Organizational citizenship behavior (OCB).

Pengaruh negatif tersebut dispesifikan pada normative commitment terhadap altruism. Sehingga sangat menarik sekali untuk meneliti organizational commitment secara mendalam guna mengetahui apakah pengaruh dampak positif atau negative dalam mempengaruhi Organizational citizenship behavior (OCB).

Berdasarkan latar belakang diatas, maka penulis tertatik untuk mengadakan penelitian yang berjudul: Pengaruh Organizational Trust dan Organizational Commitment Terhadap Organizational Citizenship Behavior (OCB) Karyawan BPJS Ketenagakerjaan Kota Bogor.

\section{Tujuan penelitian}

Adapun maksud dan tujuan penelitian ini adalah sebagai berikut:

1 Untuk mengetahui apakah terdapat pengaruh positif organizational trust terhadap organizational citizenship behavior karyawan BPJS Ketenagakerjaan Kota Bogor.

2 Untuk mengetahui apakah terdapat pengaruh positif organizational commitment terhadap organizational citizenship behavior karyawan BPJS Ketenagakerjaan Kota Bogor.

3 Untuk mengetahui apakah terdapat pengaruh positif yang secara simultan organizational trust dan organizational commitment secara simultan terhadap organizational citizenship behavior karyawan BPJS Ketenagakerjaan Kota Bogor. 


\section{Hipotesis}

Berdasarkan kerangka pemikiran penelitian, maka hipotesis dari penelitian ini sebagai berikut:

H1: Organizational Trust berpengaruh positif terhadap Organizational Citizenship Behavior.

H2: Organizational Commitment berpengaruh terhadap Organizational Citizenship Behavior.

H3: Organizational Trust dan Organizational Commitment berpengaruh positif terhadap Organizational Citizenship Behavior.

\section{Metode Penelitian}

Metode yang digunakan dalam penelitian ini adalah tipe penelitian deskriptif dengan pendekatan kuantitatif. berarti data yang dianalisis dan diolah untuk mendapatkan hasil dan kesimpulan adalah sebagai berikut:

\section{Kuesioner}

Kuesioner, yaitu suatu cara pengumpulan data yang dilakukan dengan cara mendistribusikan kuesioner kepada responden. Pada penelitian ini, kuesioner dibagikan kepada responden selanjutnya diwawancarai di lokasi penjualan untuk memudahkan pendataan

\section{Analisis Deskriptif}

Analisis deskriptif memiliki tujuan untuk memberikan gambaran (deskripsi) mengenai suatu data agar data yang tersaji menjadi mudah dipahami dan informatif. Adapun data yang disajikan adalah tanggapan dari 50 responden terhadap item-item kuesioner yang terbagi menjadi 11 item organizational trust, 9 item organizational commitment Dan 10 item organizational citizenship behavior.dengan pengukuran skala likert.

\section{Uji Validitas}

Uji validitas adalah sebuah instrumen dikatakan valid jika mampu mengukur apa yang hendak diukur dari variabel yang diteliti. Teknik yang digunakan untuk uji validitas ini adalah "korelasi product moment" dari pearson dengan tingkat kepercayaan 95\% $(\alpha=0,05)$ dilakukan dengan cara mengkorelasikan skor masingmasing item dengan skor totalnya.

\section{Uji Reabilitas}

Reliabilitas merupakan suatu alat yang memberikan hasil yang tetap sama atau konsisten. Hasil pengukuran itu harus tetap sama (relatif sama) jika pengukurannya diberikan pada subyek yang sama meskipun dilakukan oleh orang, waktu, dan tempat yang berbeda menurut Sugiyono, (2010, hlm. 183).

\section{Korelasi}

Korelasi merupakan angka yang menunjukan arah dan kuatnya hubungan antara dua variabel atau lebih. Arah dinyatakan dalam bentuk positif atau negatif, sedangkan kuatnya hubungan dinyatakan dalam besarnya koefisien korelasi dijelaskan oleh Sugiyono, (2015, hlm. 230).

\section{Analisis Regresi}

Regresi merupakan suatu analisis yang digunakan untuk melihat sifat hubungan satu atau lebih variabel bebas (X) terhadap variabel tidak bebas (Y). Dengan maksud untuk meramalkan nilai variabel tidak bebas.

\section{Koefisien Determinasi}

Menurut Sugiyono, (2012, hlm. 231)"Koefisien Determinasi yang besarnya adalah kuadrat koefisien korelasi $\left(\mathrm{r}^{2}\right)$. Koefisien ini disebut koefisien penentu, karena varians yang terjadi pada variabel dependen dapat dijelaskan melalui varians yang terjadi pada variabel independen. Koefisien determinan terletak antara 0 dan 
1. Jika nilai $\mathrm{R}^{2}$ sama dengan 1 , pendekatan itu benar-benar tepat (sempurna).

\section{Hasil dan pembahasan}

Hasil uji validitas terhadap Organizational Trust (X1)

Tabel 1

Hasil uji validitas X1

\begin{tabular}{cccc}
\hline $\begin{array}{c}\text { Butir } \\
\text { Kuesioner }\end{array}$ & $\begin{array}{c}\text { Nilai } \\
\text { Korelasi }\end{array}$ & $\begin{array}{c}\text { Nilai r- } \\
\text { tabel }\end{array}$ & $\begin{array}{c}\text { Keteranga } \\
\mathrm{n}\end{array}$ \\
\hline $\mathrm{X} 1.1$ &, 773 & 0.284 & VALID \\
\hline $\mathrm{X} 1.2$ &, 559 & 0.284 & VALID \\
\hline $\mathrm{X} 1.3$ &, 760 & 0.284 & VALID \\
\hline $\mathrm{X} 1.4$ &, 766 & 0.284 & VALID \\
\hline $\mathrm{X} 1.5$ &, 472 & 0.284 & VALID \\
\hline $\mathrm{X} 1.6$ &, 490 & 0.284 & VALID \\
\hline $\mathrm{X} 1.7$ &, 773 & 0.284 & VALID \\
\hline $\mathrm{X} 1.8$ &, 559 & 0.284 & VALID \\
\hline $\mathrm{X} 1.9$ &, 490 & 0.284 & VALID \\
\hline $\mathrm{X} 1.10$ &, 754 & 0.284 & VALID \\
\hline $\mathrm{X} 1.11$ &, 523 & 0.284 & VALID
\end{tabular}

(Sumber : Data Primer diolah)

Dari tabel diatas diketahui bahwa untuk variabel Organizational Trust dengan 11 pertanyaan yang ada dalam instrumen penelitian ini dinyatakan valid, semua butir pertanyaan memiliki nilai korelasi $>$ r-tabel dengan $r$-tabel $(n=48)=0,284$

\section{Hasil uji validitas terhadap Organizational Commitment (X2)}

Tabel 2

Hasil uji validitas X2

\begin{tabular}{crrr}
\hline $\begin{array}{c}\text { Butir } \\
\text { Kuesioner }\end{array}$ & $\begin{array}{c}\text { Nilai } \\
\text { Korelasi }\end{array}$ & $\begin{array}{c}\text { Nilai r- } \\
\text { tabel }\end{array}$ & Keterangan \\
\hline $\mathrm{X} 2.1$ &, 674 & 0.284 & VALID \\
\hline $\mathrm{X} 2.2$ &, 665 & 0.284 & VALID \\
\hline $\mathrm{X} 2.3$ &, 835 & 0.284 & VALID \\
\hline $\mathrm{X} 2.4$ &, 849 & 0.284 & VALID \\
\hline $\mathrm{X} 2.5$ &, 761 & 0.284 & VALID \\
\hline $\mathrm{X} 2.6$ &, 746 & 0.284 & VALID \\
\hline $\mathrm{X} 2.7$ &, 822 & 0.284 & VALID \\
\hline $\mathrm{X} 2.8$ &, 583 & 0.284 & VALID \\
\hline $\mathrm{X} 2.9$ &, 706 & 0.284 & VALID \\
\hline
\end{tabular}

(Sumber : Data Primer diolah)
Dari tabel diatas diketahui bahwa untuk variabel Organizational Trust dengan 11 pertanyaan yang ada dalam instrumen penelitian ini dinyatakan valid, semua butir pertanyaan memiliki nilai korelasi > r-tabel dengan $r$-tabel $(n=48)=0,284$.

Tabel 3

Hasil uji validitas $\mathrm{Y}$

\begin{tabular}{cccc}
\hline $\begin{array}{c}\text { Butir } \\
\text { Kuesioner }\end{array}$ & $\begin{array}{c}\text { Nilai } \\
\text { Korelasi }\end{array}$ & $\begin{array}{c}\text { Nilai r- } \\
\text { tabel }\end{array}$ & Keterangan \\
\hline Y.1 &, 896 & 0.284 & VALID \\
\hline Y.2 &, 484 & 0.284 & VALID \\
\hline Y.3 &, 873 & 0.284 & VALID \\
\hline Y.4 &, 838 & 0.284 & VALID \\
\hline Y.5 &, 628 & 0.284 & VALID \\
\hline Y.6 &, 898 & 0.284 & VALID \\
\hline Y.7 &, 898 & 0.284 & VALID \\
\hline Y.8 &, 488 & 0.284 & VALID \\
\hline Y.9 &, 628 & 0.284 & VALID \\
\hline Y.10 &, 301 & 0.284 & VALID \\
\hline Sum
\end{tabular}

(Sumber : Data Primer diolah)

Dari tabel diatas diketahui bahwa untuk variabel Organizational Citizenship Beharvior (Y) dengan 10 pertanyaan yang ada dalam instrumen penelitian ini dinyatakan valid, semua butir pertanyaan memiliki nilai korelasi > r-tabel dengan $\mathrm{r}$ tabel $(n=48)=0,284$.

\section{Hasil Uji Reliabilitas variabel Organizational Trust (X1)}

Jika dilihat dari nilai Cronbanch Alfa yang dihasilkan yaitu 0,899, maka dapat disimpulkan bahwa pernyataan dalam kuesioner variabel Organizational Trust (X1) adalah Reliabel dan dapat diterima.

\section{Hasil Uji Reliabilitas variabel Organizational Commitment (X2)}

Jika dilihat dari nilai Cronbanch Alfa yang dihasilkan yaitu 0,924, maka dapat disimpulkan bahwa pernyataan dalam kuesioner variabel Organizational Commitment (X2) adalah Reliabel dan dapat diterima 


\section{Hasil Uji Reliabilitas variabel Organizational Citizenship Beharvior (Y)}

Jika dilihat dari nilai Cronbanch Alfa yang dihasilkan yaitu 0,916, maka dapat disimpulkan bahwa pernyataan dalam kuesioner variabel Organizational Citizenship Behavior (Y) adalah Reliabel dan dapat diterima. Dari hasil uji coba yang telah dilakukan dapat diketahui bahwa hasil Cronbanch's Alfa setiap variabel lebih dari standar minimal Cronbanch's Alfa yang disyaratkan yaitu 0,60 , maka variabel Organizational Trust, Organizational Commitmen dan OCB adalah reliabel, dengan nilai koefisien Alfa untuk variabel (X1) sebesar 0,899, (X2) 0,924 dan (Y) 0,916 berarti jika kita lakukan penelitian yang sama dengan tujuan yang sama dan karakteristik responden yang sama, maka hasil pengambilan data berikutnya akan kita dapatkan respon yang kurang lebih sama.

Analisis Inferentif

Hasil analisis korelasi antara Organizational Trust (X1) terhadap Organizational Citizenship Behavior (Y).

Hasil perhitungan analisis korelasi diketahui $\mathrm{R}=0.678$ terletak pada interval (0.60-0.799) hal ini menunjukan bahwa hubungan antara variabel X1 terhadap Y adalah kuat dan positif. Berarti apabila X1 naik maka Y juga naik.

\section{Hasil analisis Regresi antara Organizational Trust (X1) terhadap Organizational Citizenship Behavior (Y)}

Diketahui persamaan regresi sebagai berikut $\mathrm{Y}=12,862+0,667$

Interpretasi dari persamaan tersebut adalah sebagai berikut:

intercept atau konstanta sebesar 12,862 berarti, apabila variabel bebas X1 (Organizational Trust) sama dengan 0 , maka besar variabel Y (OCB) adalah 12,862. Angka arah atau koefisien regresi variabel X1 (Organizational Trust) sebesar 0,667 ini berarti pengaruh Organizational Trust terhadap OCB adalah positif atau setiap kenaikan nilai skor variabel X1 Organizational Trust sebesar 1, maka akan meningkat nilai skor variabel Y (OCB) sebesar 0,667.

Hasil analisis koefisien Determinasi antara Organizational Trust (X1) terhadap Organizational Citizenship Behavior (Y)

Diketahui nilai $\mathrm{R}$ Squer sebesar 0,460 hal ini mengandung arti bahwa pengaruh variabel $\mathrm{X} 1$ secara simultan terhadap variabel $\mathrm{Y}$ adalah sebesar $46,0 \%$ memberikan arti bahwa Besarnya peranan Organizational Trust terhadap OCB, dan sisanya berasal dari faktor-faktor lain yang juga mempengaruhi OCB.

\section{Uji Hipotesis $\mathrm{H1}$}

Berdasarkan penghitungan dengan menggunakan aplikasi komputer diketahui bahwa nilai t-hitung sebesar 6,397 karena thitung $=6,397>\mathrm{t}$-tabel $=2.012$ sehingga dapat disimpulkan bahwa $\mathrm{H} 1$ diterima, yang berarti terdapat pengaruh yang signifikan antara X1 (Organizational Trust) terhadap $\mathrm{Y}(\mathrm{OCB})$.

Hasil analisis korelasi antara Organizational Commitment (X2) terhadap Organizational Citizenship Behavior (Y)

Diketahui $\mathrm{R}=0.177$ terletak pada interval (0.000-0.199) hal ini menunjukan bahwa hubungan antara variabel $\mathrm{X} 2$ terhadap Y adalah positif. Berarti apabila X2 naik maka Y juga naik.

Hasil analisis Regresi antara Organizational Commitment (X2) terhadap Organizational Citizenship Behavior (Y)

Diketahui persamaan regresi sebagai berikut $Y=52,434+-0,230$ Interpretasi dari 
persamaan tersebut adalah sebagai berikut: intercept atau konstanta sebesar 52,434

berarti, apabila variabel bebas X2 (Organizational Commitment) sama dengan 0 , maka besar variabel Y (OCB) adalah 52,434.Angka arah regresi variabel X2(Organizational Commitment) sebesar 0,230 ini berarti pengaruh Organizational Commitment terhadap OCB adalah positif atau setiap kenaikan nilai skor variabel X2 Organizational Commitment sebesar 1, maka akan meningkat nilai skor variabel $\mathrm{Y}$ (OCB) sebesar -0,230

Hasil analisis Koefisien Determinasi antara Organizational Commitment (X2) terhadap Organizational Citizenship Behavior (Y)

Diketahui nilai $\mathrm{R}$ Squer sebesar 0,031 hal ini mengandung arti bahwa pengaruh variabel $\mathrm{X} 2$ secara simultan terhadap variabel $\mathrm{Y}$ adalah sebesar 3,1\% memberikan arti bahwa Besarnya peranan Organizational Commitment terhadap OCB, dan sisanya berasal dari faktor-faktor lain yang juga mempengaruhi OCB.

\section{Hasil Uji t variabel X2 Organizational Commitment}

Diketahui bahwa nilai t-hitung sebesar 1,296 karena t-hitung $=-1,244<\mathrm{t}$-tabel $=$ 2.012 sehingga dapat disimpulkan bahwa $\mathrm{H} 2$ ditolak, yang berarti tidak terdapat pengaruh yang signifikan antara X2 (Organizational Commitment) terhadap $\mathrm{Y}$ (OCB).

\section{Hasil analisis Korelasi antara Organizational Trust (X1) Organizational Commitment (X2) terhadap Organizational Citizenship Behavior (Y)}

Diketahui, $\mathrm{R}=0.708$ terletak pada interval (0.60-0.799) hal ini menunjukan bahwa hubungan antara variabel Organizational Trust (X1) Organizational Commitment (X2) terhadap Organizational Citizenship
Behavior (Y) adalah kuat dan positif. Berarti apabila X1 dan X2 naik maka Y juga naik.

$\begin{array}{llrr}\text { Hasil analisis } & \text { Regresi } & \text { antara } \\ \text { Organizational } & \text { Trust (x1) } & \text { dan } \\ \text { Organizational } & \text { Commitment } & \text { (X2) }\end{array}$
terhadap Organizational Citizenship Behavior (Y).

Diketahui persamaan regresi sebagai berikut $\mathrm{Y}=22,482+0,675+-0,265$ Interpretasi dari persamaan tersebut adalah sebagai berikut: intercept atau konstanta sebesar 22,482 berarti, apabila variabel bebas X1 (Organizational Trust) dan X2 (Organizational Commitment) sama dengan 0 , maka besar variabel Y (OCB) adalah 22,482 .

Angka arah regresi variabel bebas X1 (Organizational Trust) sebesar 0,675 ini berarti bahwa pengaruh X1 terhadap Y adalah positif. Dan X2 (Organizational Commitment) sebesar $-0,265$ ini berarti bahwa pengaruh X2 terhadap $\mathrm{Y}$ adalah positif, atau setiap kenaikan nilai skor variabel X1 (Organizational Trust) dan X2 Organizational Commitment sebesar 1, maka akan meningkat nilai skor variabel Y (OCB).

Hasil analisis Koefisien Determinasi antara Organizational Trust dan Organizational Commitment (X2) terhadap Organizational Citizenship Behavior (Y).

Diketahui nilai $\mathrm{R}$ Squer sebesar 0,502 hal ini mengandung arti bahwa pengaruh variabel $\mathrm{X} 1$ dan $\mathrm{X} 2$ secara simultan terhadap variabel $\mathrm{Y}$ adalah sebesar 50,2\% memberikan arti bahwa Besarnya peranan Organizational Trust dan Organizational Commitment terhadap OCB, dan sisanya berasal dari faktor-faktor lain yang juga mempengaruhi OCB.

Hasil Uji F variabel Organizational Trust X1 dan X2 Organizational Commitment 
Diketahui nilai signifikansi untuk pengaruh X1 (Organizational Trust) dan $\mathrm{X} 2$ (Organizational Commitment) secara simultan terhadap Y (OCB) adalah sebesar $0,000<$ dari 0,005 dan nilai $F$ hitung sebesar 23,662 > dari $\mathrm{F}$ tabel 3,19 sehingga dapat disimpulkan bahwa $\mathrm{H} 3$ diterima yang berarti terdapat pengaruh X1 (Organizational Trust) dan X2(Organizational Commitment) secara simultan terhadap Y.

\section{Kesimpulan}

Berdasarkan analisa tentang Pengaruh Organizational Trust dan Organizational Commitment terhadap Organizational Citizenship Behavior serta didukung teoriteori dan pembahasan pada bab-bab sebelumnya maka dapat disimpulkan bahwa : Organizational Trust dan Organizational Commitment memiliki pengaruh terhadap Organizational Citizenship Behavior. Hal tersebut dibuktikan sebagai berikut:

1. Diketahui persamaan regresinya adalah $\mathrm{Y}=12,862+0,667$. intercept atau konstanta sebesar 12,862 berarti, apabila variabel bebas X1 (Organizational Trust) sama dengan 0 , maka besar variabel Y (OCB) adalah 12,862 dan nilai konstanta X1adalah 0,667. Koefisien determinasi diketahui nilai $\mathrm{R}$ Squer sebesar 0,460 hal ini mengandung arti bahwa pengaruh variabel X1 secara simultan terhadap variabel $\mathrm{Y}$ adalah sebesar 46,0\%. Hasil Uji t: Hasil uji t untuk variabel X1 Organizational Trust diketahui bahwa nilai t-hitung sebesar 6,397 karena t-hitung $=6,397>\mathrm{t}$-tabel $=2.012$ sehingga dapat disimpulkan bahwa H1 diterima, yang berarti terdapat pengaruh yang signifikan antara X1 (Organizational Trust) terhadap Y (OCB).

2. Diketahui persamaan regresinya adalah Y $\mathrm{Y}=$ 52,434+ -0,230: intercept atau konstanta sebesar 52,434 berarti, apabila variabel bebas X2 (Organizational
Commitment) sama dengan 0 , maka besar variabel Y (OCB) adalah 52,434 dan nilai konstanta X2 adalah -0,230. Koefisien Determinasi diketahui nilai R Squer sebesar 0,031 hal ini mengandung arti bahwa pengaruh variabel X2 secara simultan terhadap variabel $\mathrm{Y}$ adalah sebesar $3,1 \%$. Hasil Uji t: Hasil uji t untuk variabel X2 Organizational Commitment diketahui bahwa nilai t-hitung sebesar -1,244 karena thitung $=1,244<\mathrm{t}$-tabel $=2.012$ sehingga dapat disimpulkan bahwa $\mathrm{H} 2$ ditolak, yang berarti tidak terdapat pengaruh yang signifikan antara X2 (Organizational Commitment) terhadap Y (OCB).

3. Diketahui persamaan regresinya adalah $\mathrm{Y}=22,482+0,675+-0,265$ intercept atau konstanta sebesar 23,435 berarti, apabila variabel bebas X1 (Organizational Trust) dan X2 (Organizational Commitment) sama dengan 0 , maka besar variabel Y (OCB) adalah 22,482 dan nilai konstanta X1 0,675 dan X2 adalah -0,265. Koefisien Determinasi diketahui nilai R Squer sebesar 0,502 hal ini mengandung arti bahwa pengaruh variabel $\mathrm{X} 1$ dan $\mathrm{X} 2$ secara simultan terhadap variabel $\mathrm{Y}$ adalah sebesar $50,2 \%$. Hasil Uji f: diketahui bahwa diketahui nilai signifikansi untuk pengaruh X1 (Organizational Trust) dan X2 (Organizational Commitment) secara simultan terhadap Y (OCB) adalah sebesar $0,000<$ dari 0,005 dan nilai $F$ hitung 23,662 $>$ F tabel 3,19 sehingga dapat disimpulkan bahwa H3 diterima yang berarti terdapat pengaruh X1 (Organizational Trust) dan $\mathrm{X} 2$ (Organizational Commitment) secara simultan terhadap Y (OCB).

\section{Daftar Pustaka}

Fathoni, A. (2006). Manajemen Sumber Daya Manusia. Jakarta: PT Rieka Cipta

Kurniawan, A. (2015). Pengaruh komitmen organisasi terhadap organizational 
citizenship behavior (OCB) PT X Bandung. Jurnal Manajemen, 15(1), 95-118.

Luthans, F. (2006). Perilaku Organisasi (10 ed.). Yogyakarta: PT.ANDI.

Malayu, S. P. H. (2017). Manajemen Sumber Daya Manusia (Revisi ke17). Remaja Rosdakarya

Nandania, R. (2013). Peran kepercayaan organisasi dengan loyalitas karyawan di BCA Malang Raya (Undergraduate, Universitas Islam Negeri Maulana Malik Ibrahim).http://etheses.uinmalang.a c.id/1765/10/09410144_Lampiran.p df

Organ, D., Podsakoff, P., \& MacKenzie, S. (2006). Organizational Citizenship Behavior: Its Nature, Antecedents, and Consequences. https://doi.org/10.4135/9781452231 082

Robbins, Stehen. p. (2007). Perilaku Organisasi (sepuluh). PT.Macan Jaya Cemerlang.

Serap Altuntas BSN, P., Ulku Baykal BSN, P., Altuntas, S., \& Baykal, U. (2010).Relationship Between Nurses' Organizational Trust Levels and Their Organizational Citizenship Behaviors. Journal of Nursing Scholarship, 42, 186-194. https://doi.org/10.1111/j.15475069.2010.01347.x

Sugiyono, D. (2010). Metode penelitian kuantitatif kualitatif dan $\mathrm{R}$ dan $\mathrm{D}$. Alfabeta: Bandung.

Sugiyono, D. (2015). Statistika untuk penelitian. Bandung: Alfabeta

Sugiyono, D. (2012). Metode penelitian bisnis. Bandung: Alfabeta.. 